\title{
Method development, validation, and stability studies of teneligliptin by RP-HPLC and identification of degradation products by UPLC tandem mass spectroscopy
}

\author{
T. N. V. Ganesh Kumar ${ }^{* *}$, S. Vidyadhara', Niteen Ashok Narkhede², Y. Sai Silpa ${ }^{1}$ and M. Ra'va L shmi
}

\begin{abstract}
Background: Teneligliptin is a new FDA approved drug for treating Diabetes $\mathrm{Nh}$ litus. There are no reported evidences for their identified degradation products and their effects on ha

Methods: A simple and new stability indicating RP-HPLC method was develop and validated for identification of Teneligliptin and its degradants on Kromasil 100- 5C18 (250×4.6mm, solupn using pH 6.0 phosphate buffer and acetonitrile $(60: 40 \mathrm{v} / \mathrm{v})$ as a mobile phase in isocratic mode of elution at a flow rate of $1.0 \mathrm{~mL} / \mathrm{min}$. The column effluents were monitored by a variable wavelength UV detector at $246 \mathrm{rm}$. The method was validated as per ICH guidelines. Forced degradation studies of Teneligliptin wer carm out under acidic, basic, neutral (peroxide), photo and thermal conditions for 48 hours at room temperature. deg dation products were identified by HPLC and characterized by UPLC with tandem mass spectroscopy (LC/M. 15).

Results: UPLC MS/MS data shown major peaks, fe-1ved at 375.72, 354.30, 310.30, 214.19, 155.65, 138.08 and $136.18 \mathrm{~m} / \mathrm{z}$.

Conclusion: Degradation was observed $n \mathrm{~b} \sim$, peroxide and thermal stressed samples, but not in acid and photolytic stressed samples.

Keywords: Teneligliptin, Degradat n, RP-HPLC, LC/MS
\end{abstract}

\section{Background}

Teneligliptin is a novel $\mathrm{d} \cdot \mathrm{n}, \mathrm{g}$, wh $\mathrm{h}$ is used for the treatment of type 2 diab tes ellitu. It is an antidiabetic drug that belongs to a vur, peptidase-4 inhibitors or "gliptins" (Kishi oto 201 Chemically, it is $\{(2 \mathrm{~S}, 4 \mathrm{~S})-4$ [4-(3-methyl - pl vl-1H pyrazol-5-yl)-1-piperazinyl]-2pyrrolidin y (1, 3-t. Lolidin-3-yl) methanone (Fig. 1). Tenelic ti exerts its activity for $24 \mathrm{~h}$, with elevation of activa glu agon-like peptide 1 (GLP-1) levels by sapp ssing ostprandial hyperglycemia after the meals nd Kadowaki 2013; Ideta et al. 2015; Bronson et al. 13). Significant decrease in hemoglobin A1c (HbA $1 \mathrm{c})$, fasting blood glucose, and postprandial blood

\footnotetext{
* Correspondence: ganeshtnv@gmail.com

1 Department of Pharmaceutical Analysis, Chebrolu Hanumaiah Institute of

Pharmaceutical Sciences, Guntur, Andhra Pradesh 522019, India

Full list of author information is available at the end of the article
}

glucose levels was observed in type 2 diabetic patients taking teneligliptin for 12 weeks (Goda and Kadowaki 2013). This drug showed a promising effect in stabilizing the glycemic fluctuations throughout the day and suppressing the diabetic complications (Ideta et al. 2015). Teneligliptin is approved for use in India, Japan, and Korea in 2012 (Bronson et al. 2013). Although the drug entered the market, there is no much information available about its degradation studies and its degraded products. Few have reported its metabolism and pharmacokinetic studies (Halabi et al. 2013; Reddy and Rao 2014; Luhar et al. 2016; Shanthikumar et al. 2015). Identification of the degraded products helps in future metabolic studies and also related impurity determination during its bulk synthesis. In the present study, we have focused our research into two stages: (1) to develop and validate a reversed-phase HPLC (RP-HPLC) 


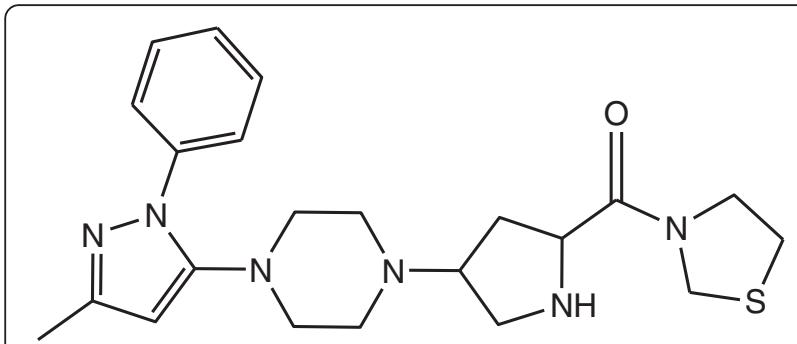

Fig. 1 Structure of teneligliptin

method for identifying the teneligliptin and its degradation products formed during various forced conditions as per the ICH guidelines (Asian Guideline for Validation of Analytical Procedure Adopted from ICH guideline, Q2A27, and ICH Q2B 1994) and (2) identification of the degraded products obtained and their characterization using ultra-performance liquid chromatography (UPLC) with tandem mass spectroscopy (LC/MS/MS).

\section{Methods}

\section{Materials and reagents}

HPLC grade acetonitrile (Lichrosolv ${ }^{\circledR}$, Merck Life Science, Pvt. Ltd., Mumbai, India), HPLC water (Lichrosolv ${ }^{\oplus}$, Merck Life Science, Pvt. Ltd., Mumbai, India), formic acid and potassium dihydrogen $o$-phosphate (Thermo Fisher Sr, entific Pvt. Ltd., Mumbai, India), and sodium hydroxi. ' $S$ '? Fine-Chem. Ltd., Mumbai, India) were used for che st Teneligliptin pure drug and its tablet form 4 ion wer obtained from Ajanta Pharma Limited, Mumbai, . 'ia.

\section{Apparatus}

The HPLC system (Agilent Technol `, Crmpact LCG4286A made in Germany) wi rariable wavelength UV detector was used. Reversed-phase masil ${ }^{\circ}$ 100-5-C18 $(250 \times 4.6 \mathrm{~mm}, 5-\mu \mathrm{m}$ p $\mathrm{e}$ siz $)$ column was used for chromatographic ser tio The chromatographic and integrated data we rec ted using EZChrom Elite Compact Software i mputea system (Version 3.30B, Sr. no. 08051601100, Scic. fic Software, Inc.). For the LC/MS

Table 1.

\begin{tabular}{lll}
\hline Con & Peak height (mAv) & Retention time (min) \\
\hline 300 & 1288 & 4.04 \\
300 & 1273 & 4.04 \\
300 & 1282 & 4.03 \\
300 & 1266 & 4.03 \\
300 & 1257 & 4.04 \\
Average & 1280 & 4.05 \\
Standard deviation & 1274.33 & \\
\% RSD & 11.3959 & \\
\hline
\end{tabular}

Table 2 Linearity of teneligliptin

\begin{tabular}{lll}
\hline Concentration $(\mu \mathrm{g} / \mathrm{mL})$ & Peak height $(\mathrm{mAv})$ & Retention time $(\mathrm{min})$ \\
\hline 100 & 0452 & 4.09 \\
200 & 0854 & 4.06 \\
300 & 1246 & 4.06 \\
400 & 1691 & 4.05 \\
500 & 2052 & 4.04 \\
\hline
\end{tabular}

studies, UPLC system consisting of graa + mode pump with column Acquity UPLC@ BEH C18 ( $\mu_{1}, 2.1 \times$ $50 \mathrm{~mm}$ ) detected using photo dior e array $(\mathrm{PD}, \mathrm{A})$ detector range 200-400 $\mathrm{nm}$ was used $\mathrm{Tl}$ mass pectrum with electrospray ionization (ESI) de o. nzation was used for the study (LC/MS/MS (Wate XEVO-TQD).

\section{Chromatographic condition}

Chromatographic s aration was achieved on Kromasil ${ }^{\bullet}$ 100-5-C18 usin $r \quad$ phase consisting of a mixture of pH 6.0 phosphate ffer and acetonitrile $(60: 40 v / v)$ under isocratic 1 of elution. The mobile phase was prepared and filterec th/ro, gh membrane filters $(0.45 \mu \mathrm{m})$ and sonicated for 30 min prior to use. Separation was performed us. $1 \mathrm{~mL} / \mathrm{min}$ flow rate at room temperature, and the un $\mathrm{t}$ he was $25 \mathrm{~min}$. The injection volume was $20 \mu \mathrm{L}$ the detection wavelength set at $246 \mathrm{~nm}$.

\section{LC/MS conditions}

Chromatographic separation was achieved on Acquity UPLC@ BEH C18 $1.7 \mu \mathrm{m}, 2.1 \times 50 \mathrm{~mm}$ using the gradient mobile phase consisting of A (10\% acetonitrile in water with $0.1 \%$ formic acid) and B (90\% acetonitrile with $0.1 \%$ formic acid). A flow rate of $0.3 \mathrm{~mL} / \mathrm{min}$ is maintained for the study. The eluted components were detected using PDA at a range of 200-400 nm. The products were ionized by ESI mode for their mass data.

\section{Sample preparation}

$1000 \mu \mathrm{g} / \mathrm{mL}$ solution of teneligliptin was prepared by dissolving the required amount of the drug in methanol. The solution was adequately diluted with methanol for accuracy, precision, linearity, limit of detection, and quantification studies.

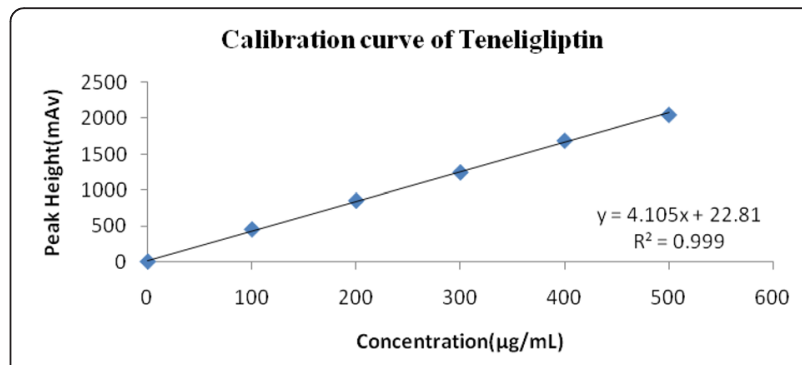

Fig. 2 Linearity of teneligliptin 
Table 3 Precision results of teneligliptin

\begin{tabular}{lll}
\hline $\begin{array}{l}\text { Concentration } \\
(\mu \mathrm{g} / \mathrm{mL})\end{array}$ & $\begin{array}{l}\text { Peak height } \\
(\mathrm{mAv})\end{array}$ & $\begin{array}{l}\text { Retention time } \\
(\mathrm{min})\end{array}$ \\
\hline 300 & 1308 & 4.04 \\
300 & 1273 & 4.04 \\
300 & 1298 & 4.06 \\
300 & 1299 & 4.11 \\
300 & 1284 & 4.04 \\
300 & 1280 & 4.05 \\
Average & 1290.33 & \\
Standard deviation & 13.366 & \\
\% RSD & 1.035 & \\
\hline
\end{tabular}

\section{Stability sample preparation}

The collected samples of acid and base hydrolysis were neutralized with sodium hydroxide and hydrochloric acid, respectively. Further dilution was carried out with methanol and the remaining stressed samples also diluted with methanol. All the samples were filtered before analysis.

\section{Degradation studies}

\section{Acid degradation}

The teneligliptin was subjected to forced degrada acid hydrolysis using $0.1 \mathrm{~N} \mathrm{HCl}$ maintained at $05^{\circ} \mathrm{C} r$ $48 \mathrm{~h}$. The sample after the stress was neutra 1 with so dium hydroxide and diluted with methanol an siltered through a $0.45-\mu \mathrm{m}$ membrane before ito analysis.

\section{Base degradation}

The teneligliptin was subject $t_{o}$ forced degradation by base hydrolysis using $0.1 \mathrm{~N}, \mathrm{~A}$ maintained at $35{ }^{\circ} \mathrm{C}$ for $48 \mathrm{~h}$. The san le after the stress was neutralized with hydr hlo acid and diluted with methanol and filured rough a $0.45-\mu \mathrm{m}$ membrane before its analy

\section{Hydroger peroxide ( $n_{t}$,tral) degradation}

Forcea r dat on of teneligliptin was studied under the fluen of $(3 \%)$ hydrogen peroxide maintained at $25^{\circ} \mathrm{C}$ for $4 \% \mathrm{~h}$. The stressed sample was diluted with

Table 4 Accuracy results of teneligliptin

\begin{tabular}{llllll}
\hline $\begin{array}{l}\text { Recovery } \\
\text { level }(\%)\end{array}$ & $\begin{array}{l}\text { Test } \\
\text { concentration } \\
(\mu \mathrm{g} / \mathrm{mL})\end{array}$ & $\begin{array}{l}\text { Standard } \\
\text { concentration } \\
(\mu \mathrm{g} / \mathrm{mL})\end{array}$ & $\begin{array}{l}\text { Total } \\
\text { concentration } \\
(\mu \mathrm{g} / \mathrm{mL})\end{array}$ & $\begin{array}{l}\text { Peak } \\
\text { intensity }\end{array}$ & $\begin{array}{l}\% \\
\text { recovery }\end{array}$ \\
\hline 80 & 200 & 100 & 300 & 1276 & 102.5 \\
100 & 200 & 200 & 400 & 1632 & 96.5 \\
120 & 200 & 300 & 500 & 2089 & 101.8 \\
\hline
\end{tabular}

Table $\mathbf{5} L O D$ and $L O Q$ results of teneligliptin

\begin{tabular}{llll}
\hline $\begin{array}{l}\text { Calibration } \\
\text { equation }\end{array}$ & $\begin{array}{l}\text { SD of the lowest } \\
\text { concentration in linearity }\end{array}$ & $\operatorname{LOD}(\mu \mathrm{g} / \mathrm{mL})$ & $\mathrm{LOQ}(\mu \mathrm{g} / \mathrm{mL})$ \\
\hline$Y=4.105 x+22.81$ & 5.03 & 4.04 & 12.259 \\
\hline
\end{tabular}

methanol and filtered through a $0.45-\mu \mathrm{m} \mathrm{mem}^{\mathrm{r}}$ rane before its analysis.

\section{Photolytic degradation}

The influence of UV light on the strivity o onfigliptin was studied by exposing the $s$ mple in $U$, light at $365 \mathrm{~nm}$ for $48 \mathrm{~h}$. The stressed si ple was diluted with methanol and filtered throug 0.4. membrane before its analysis.

\section{Thermolysis degradation}

The effect of increa demperature on teneligliptin was studied by hea or ample at $69{ }^{\circ} \mathrm{C}$ for $48 \mathrm{~h}$ in a refluxing apparat. The stressed sample was diluted with met and filtered through a $0.45-\mu \mathrm{m}$ membrane befo e its nalysis.

\section{Va. tion}

Syste, suitability

system suitability was determined by six injections of teneligliptin $(300 \mu \mathrm{g} / \mathrm{mL})$. The developed method was found to be suitable for use as the tailing factor and peak resolution for teneligliptin were within the limits.
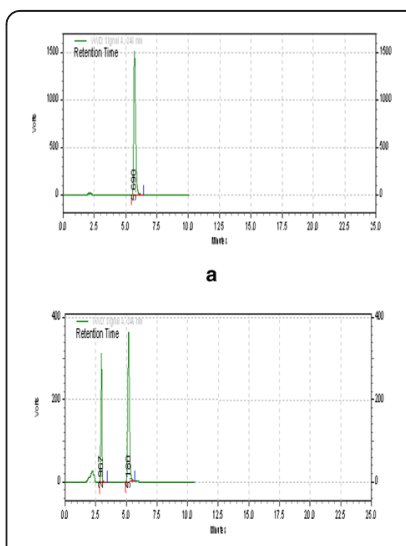

c

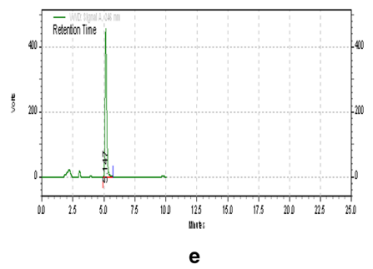

Fig. 3 Typical HPLC chromatograms of teneligliptin and its degradation products formed. a Pure drug solution. b $0.1 \mathrm{~N} \mathrm{HCl}$. c $0.1 \mathrm{~N} \mathrm{NaOH}$. d $3 \%$ hydrogen peroxide. e Photolysis UV light $365 \mathrm{~nm}$. f Thermal $60{ }^{\circ} \mathrm{C}$ 
Table 6 HPLC data of degradation studies

\begin{tabular}{|c|c|c|c|c|c|c|c|c|c|}
\hline \multirow[t]{3}{*}{ S. no. } & \multirow{3}{*}{$\begin{array}{l}\text { Stress } \\
\text { condition }\end{array}$} & \multirow{3}{*}{$\begin{array}{l}\text { Stress } \\
\text { parameters } \\
\text { used }\end{array}$} & \multirow[t]{3}{*}{ Time (h) } & \multicolumn{2}{|c|}{ Drug peak } & \multicolumn{4}{|c|}{ Degraded product peaks } \\
\hline & & & & \multirow[t]{2}{*}{$\mathrm{Rt}$} & \multirow{2}{*}{$\begin{array}{l}\text { Peak } \\
\text { intensity }\end{array}$} & \multicolumn{2}{|c|}{ Peak 1} & \multicolumn{2}{|c|}{ Peak 2} \\
\hline & & & & & & Rt & Intensity & Rt & Intensity \\
\hline 1 & Acid & $0.1 \mathrm{~N} \mathrm{HCl}$ & 48 & 5.035 & 594.73 & - & - & - & - \\
\hline 2 & Base & $0.1 \mathrm{~N} \mathrm{NaOH}$ & 48 & 5.177 & 364.46 & 2.966 & 312.129 & - & \\
\hline 3 & Oxidative & $0.3 \% \mathrm{H}_{2} \mathrm{O}_{2}$ & 48 & 5.299 & 1899.8 & 2.519 & 846.61 & 2.979 & \\
\hline 4 & Light & UV light & 48 & 5.150 & 457.29 & - & - & & \\
\hline 5 & Temperature & $60^{\circ} \mathrm{C}$ & 48 & 5.140 & 600.41 & 3.033 & 46.65 & & \\
\hline
\end{tabular}

The linearity of teneligliptin was studied from the standard concentrations ranging from 100 to $500 \mu \mathrm{g} / \mathrm{mL}$. The calibration curve of peak intensity versus concentration was plotted, and correlation coefficient and regression line equation were determined.

\section{Precision}

The precision of the method was determined by six $(n=6)$ injections of teneligliptin $(300 \mu \mathrm{g} / \mathrm{mL})$, and the \% RSD of peak areas were calculated. The obtained RSD was within the range $(\leq 2)$.
The recovery of the metho was determined by adding a known ar o of the drug to the standard concentration. The overy was performed at three levels of $80 \quad 100$, and $120 \%$ of teneligliptin standard con the three samples were prepared for eac recovery level, and \% recoveries were calc od.

Limits of det sction (LOD) and limit of quantification (LOQ)

T. OD and LOQ are the lowest level and lowest concentr ion of the analyte, respectively, in a sample that 11/ yield signal-to-noise ratios of 3.3 for LOD and 10

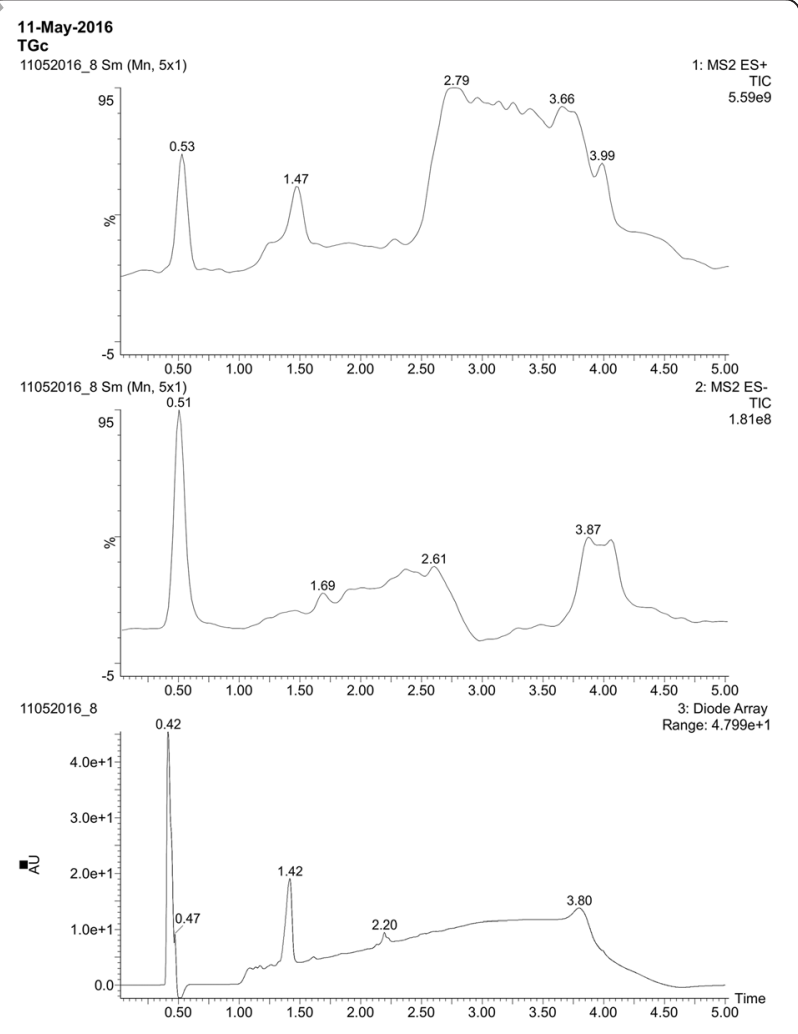

Fig. 5 UPLC data of teneligliptin and its degradation products under

hydrogen peroxide stress

11-May-2016

110520
Fig. 4 UPLC data of teneligliptin and its degradation products under base stress

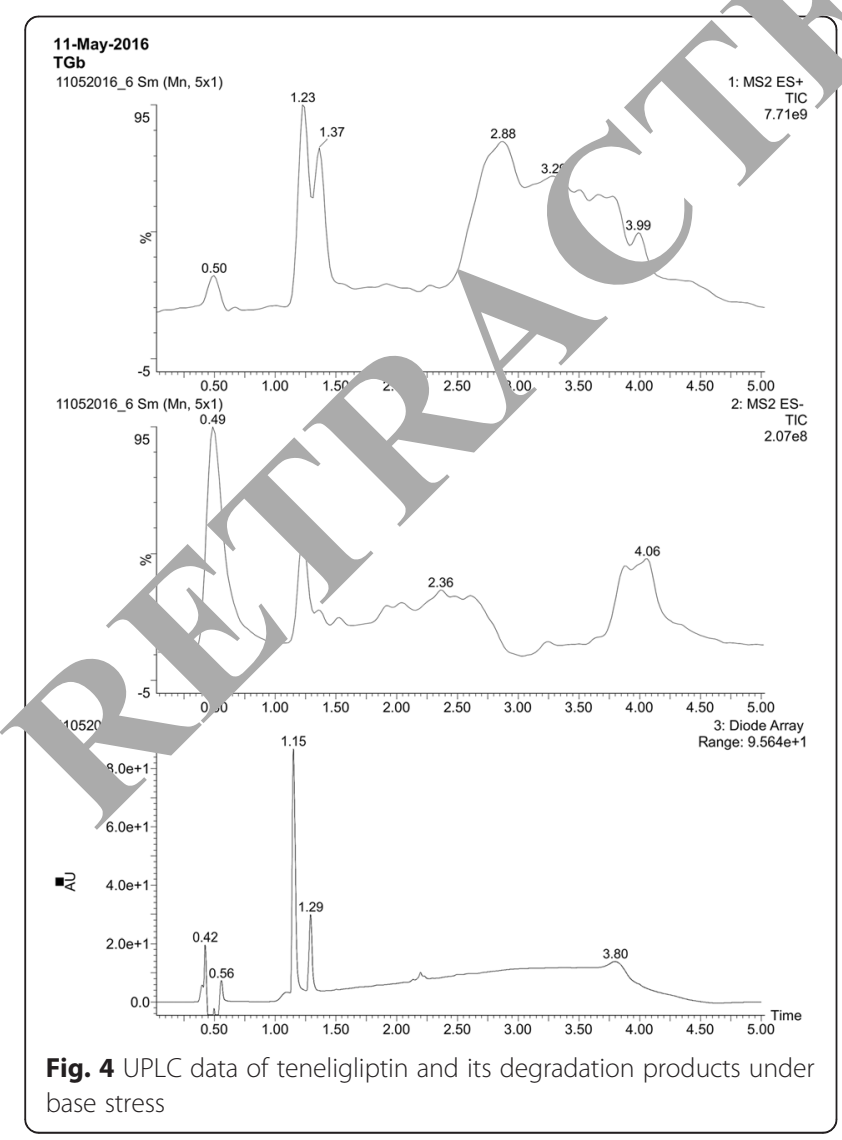


for LOQ. These are determined from the standard deviation of the peak response and the slope of the calibration curve.

\section{Results \\ Method development and optimization of chromatographic conditions}

Initially, 50:50 \% v/v of methanol and water was tried on Kromasil $^{\circ} 100-5-\mathrm{C} 18$ as a mobile phase at $1 \mathrm{~mL} /$ min flow rate and we observed that the peak was not eluted in this mobile phase. Then, 50:50 \% v/v pH 7.4 phosphate buffer (basic) and acetonitrile was tried as a mobile phase on the same column at $1 \mathrm{~mL} / \mathrm{min}$ flow rate. The peak was eluted with poor resolution and low intensity for high concentration $(1000 \mu \mathrm{g} /$ $\mathrm{mL}$ ) of the drug. Then, 50:50 \% v/v pH 6 phosphate buffer (acidic) and acetonitrile was tried as a mobile phase on $\mathrm{Kromasil}^{\circ}$ 100-5-C18, and greater intensity and peak broadening were observed. Then, for better resolution, 60:40 \% v/v pH 6 phosphate buffer and acetonitrile was modified as a mobile phase at $1 \mathrm{~mL} /$ min flow rate. Sharp peak, good intensity, and good retention time were observed in isocratic mode of elution. The system suitability was performed, and the results were found to be within the limits (Table 1\%.

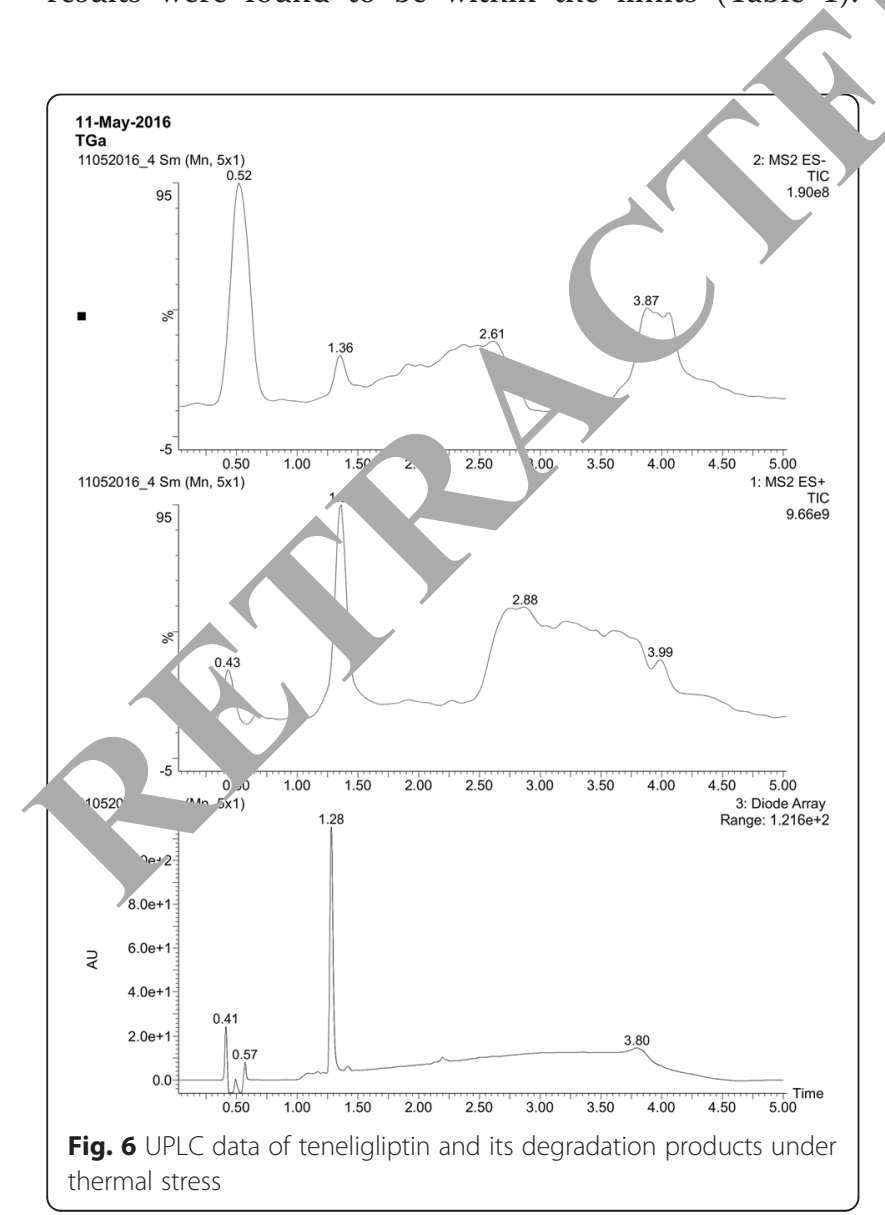

Linearity with 0.99 regression coefficient was observed at the concentration range of $100-500 \mu \mathrm{g} / \mathrm{mL}$ tabulated in Table 2, and the calibration curve is depicted in Fig. 2. The method was validated for the parameters, precision, accuracy, and LOD-LOQ as per the guidelines and tabulated the results in Tables 3,4 , and 5 , respectively. The results of validati in were within the limits.

\section{Stability studies}

Teneligliptin was stressed under dirreren corditions, and the samples were subjected to HPLC separation. Significant degradation product $\mathrm{k}$ ks were observed in basic, neutral (hydrogen pero te), nermolysis conditions. The teneliglipti was il to be stable under acidic and photolysis co 'itions. he chromatograms of pure drug and its stressea mples are shown in Fig. 3. The peak intensitie ind retention times of the degraded product peaks ri ess conditions are tabulated in Table 6. The UPL data is depicted in Figs. 4, 5, and 6 for the ba hvdrogen peroxide-, and thermally stressed samples, respec, vely. The respective mass spectra are shown in Firs. 7, 8, and 9. From the mass spectral data, thu agmentation pattern of teneligliptin was depicted. The agmentation patterns of the base-, peroxide-, and

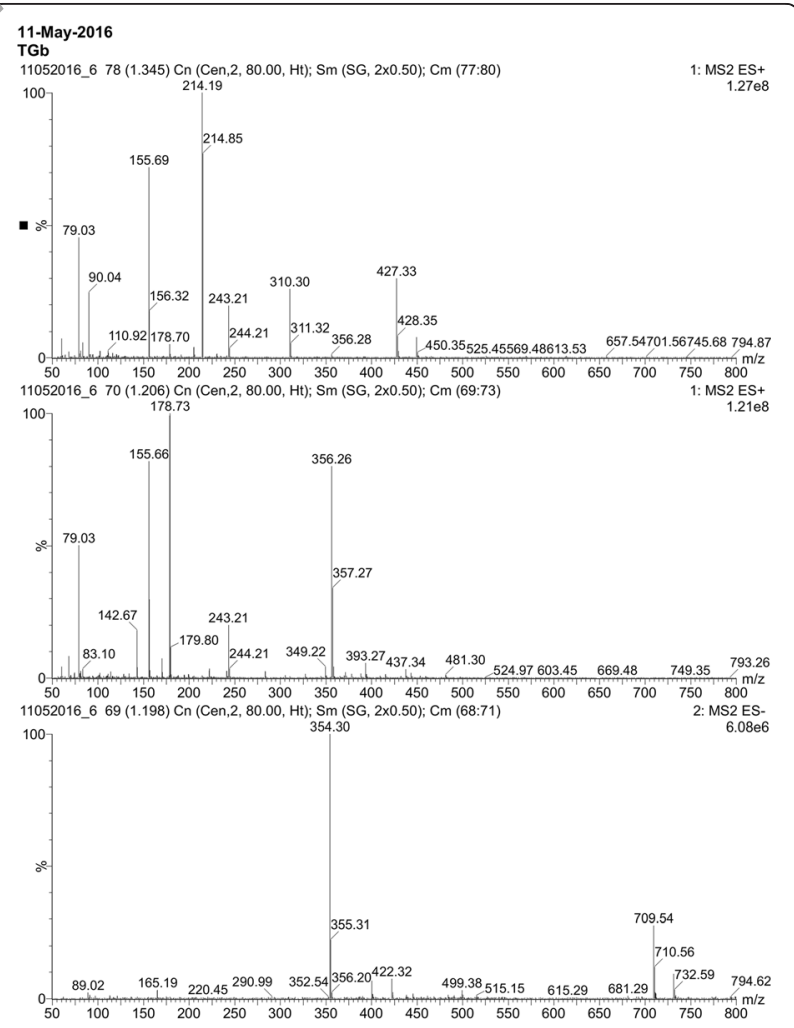

Fig. 7 LC/MS/MS-ESI data of teneligliptin and its degradation products under base stress 


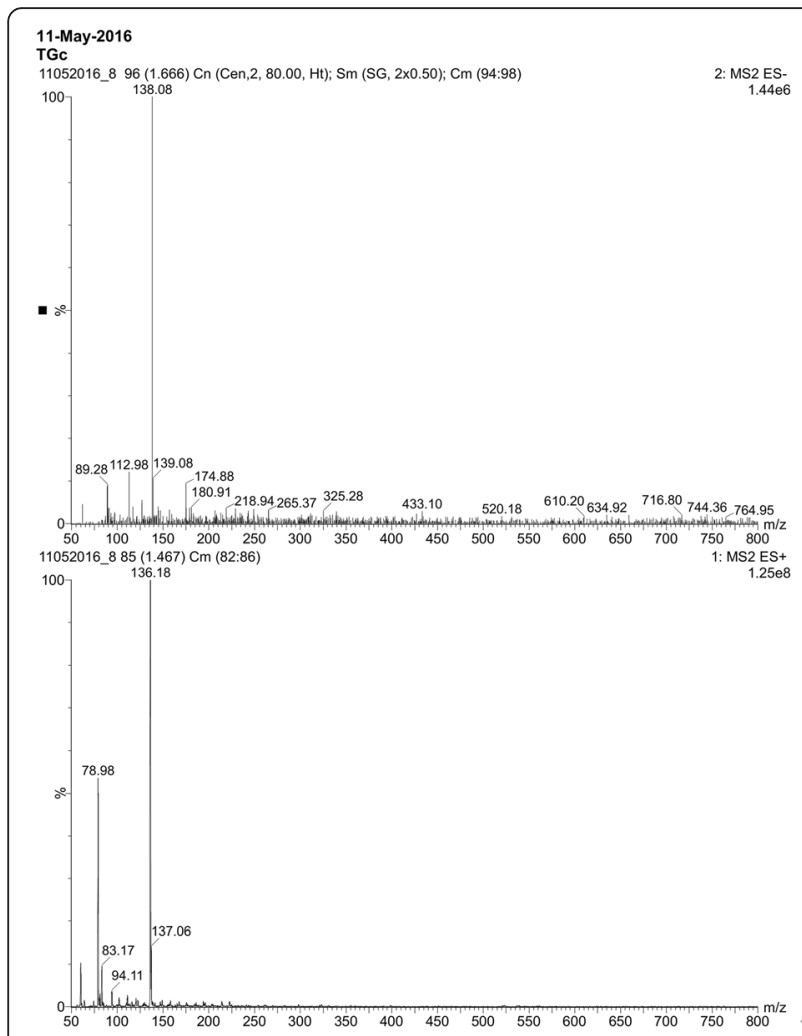

Fig. $8 \mathrm{LC} / \mathrm{MS} / \mathrm{MS}-\mathrm{ESI}$ data of teneligliptin and its degradation products under hydrogen peroxide stress

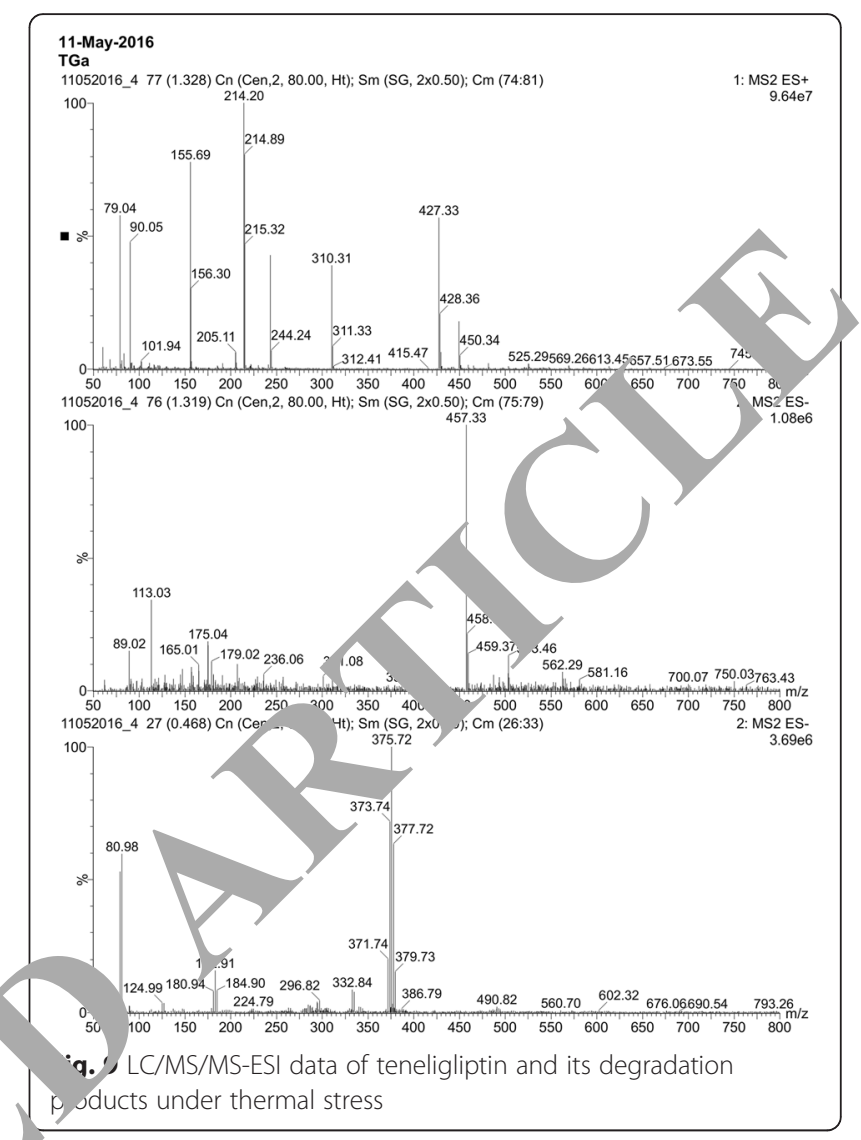

a method for its estimation and identification by RPHPLC. A new RP-HPLC method was developed and validated for teneligliptin as per the $\mathrm{ICH}$ guidelines and used as a stability-indicating method. The teneligliptin pure drug was used for the study and stressed under

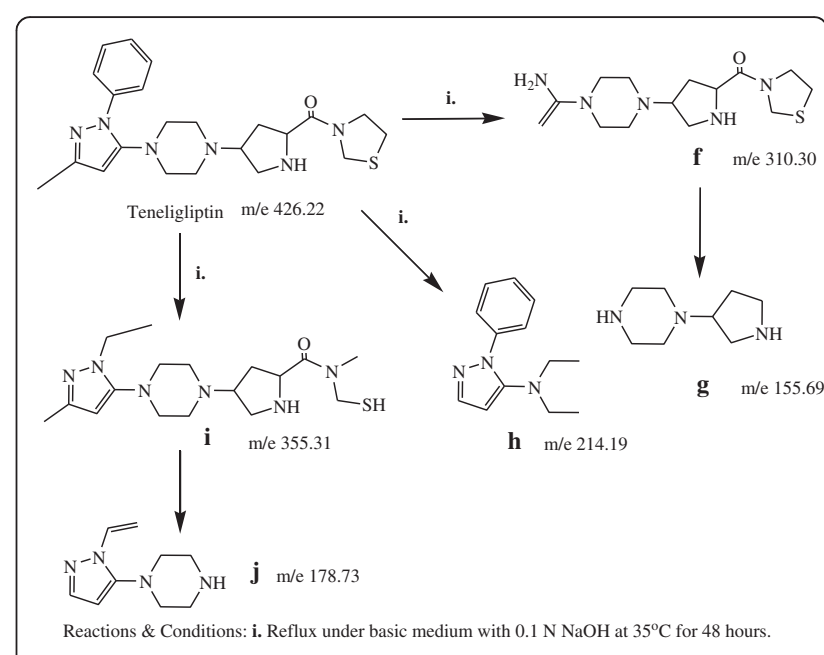

Fig. 10 Fragmentation pattern depiction of teneligliptin under base stress 


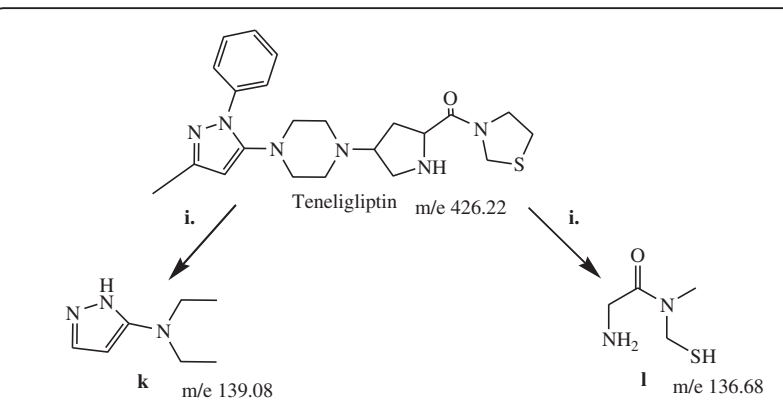

Reactions \& Conditions: i. Reflux with presence of $3 \%$ hydrogen peroxide at $35^{\circ} \mathrm{C}$ for 48 hours.

Fig. 11 Fragmentation pattern depiction of teneligliptin under hydrogen peroxide stress

acid, base, neutral (hydrogen peroxide), UV photolysis, and thermal conditions. The HPLC analysis of the stressed samples has shown that no degradation occurred under the influence of acid and UV light. But the stressed samples under base, peroxide, and thermal have presence of the degraded products, which was observed as separate peaks in HPLC other than the teneligliptin. The obtained degraded samples were further analyzed by UPLC/MS/MS, to identify the products formed. The major molecular ion fragments formed for all the three stress conditions are dif ent except 310.30 ((4-(4-(1-aminovinyl)piper inyl)pyrrolidin-2-yl)(thiazolidin-3-yl)methanone), 21 r.19 ( diethyl-1-phenyl-1H-pyrazol-5-amine), and 15, (1-(py, rolidin-3-yl)piperazine) were observed in both e and thermal stress conditions. A characteri cic 354.30 (4/4-(1ethyl-3-methyl-1H-pyrazol-5-yl)pipera n-1-yl)-N-(mercaptomethyl)-N-methylpyrrolidine-2-carbc nide and 375.72 ((4-(4-(3-methyl-1-vinyl-1H-pyra $\quad$-5-yl)piperazin-1-yl)pyrrolidin-2-yl)(thiazolidin-3-yl)meth no ... Molecular ion peak was observed in base condition,

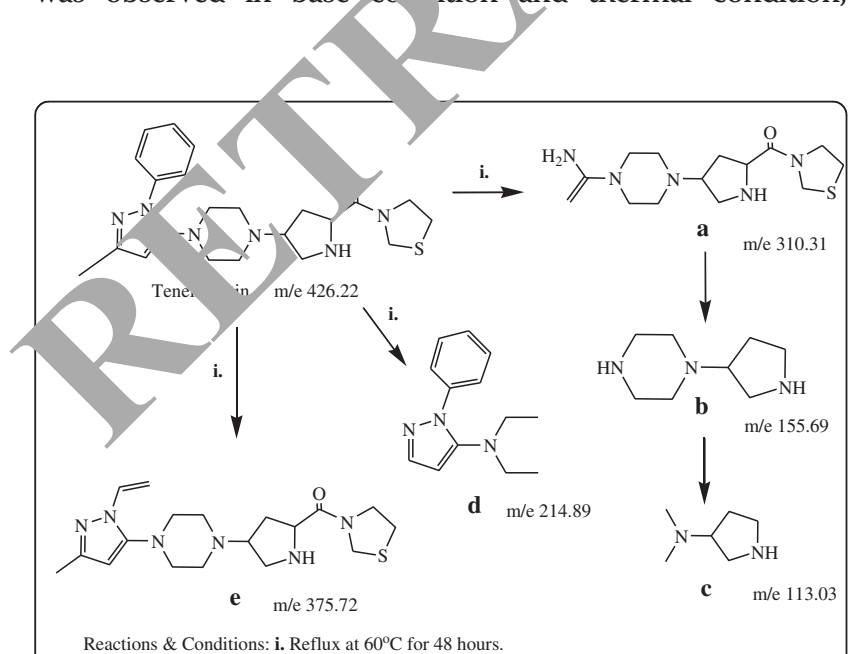

Fig. 12 Fragmentation pattern depiction of teneligliptin under thermal stress respectively. The products formed with photolytic stress were completely different with molecular ions at 138.08 (N,N-diethyl-1H-pyrazol-5-amine) and 136.18 (2-amino$\mathrm{N}$-(mercaptomethyl)-N-methylacetamide), which are not observed in other stress conditions. From the data, it is observed that comparatively less degradation occurred for photolysis stress than for base and thermal stress. The fragmentation pattern shows that degraded products are similar for the base and th nal stress samples. Further study is requi for determining the degraded products' toxicity vy qu tify ing the samples.

\section{Conclusions}

The present study hel, s in ic tifying the degraded products of tenelig' $\mathrm{p}_{\mathrm{u}}$ in bu/k and formulations, during their storage ana ansport conditions. This research work $1 \mathrm{~S} \mathrm{~L}$. first to report its stability studies with degl 'or duct identification, which is helpful for deter ning the toxicity of the degraded products also to caution the storage conditions. The prodicts 1 ormed could also be the starting materials during its synthesis, which has to be studied. Fu. er study is required for establishing the toxicity rofi of the degraded products, which is under r. crss.

\section{cknowledgements}

The authors are thankful to the Chebrolu Hanumaiah Institute of Pharmaceutical Sciences, Guntur, and CSIR-Indian Institute Integrative Medicine, Mumbai, for providing the facilities and timely support for carrying out this research work.

\section{Authors' contributions}

TNVGK conceived the main idea and implementation of the work by selecting the drug and performed the wet lab study. TNVGK also analyzed the degradation products and interpreted the results from the LC/MS/MS data. SV helped in analyzing the results of the RP-HPLC method development and validation. NAN performed the LC/MS study of the samples and helped in the UPLC method development. YSS performed the wet lab study of the hydrogen peroxide stress and thermal stress work for the drug sample. YSS also helped in adjusting the $\mathrm{pH}$ of the mobile phase during the HPLC study. MRL performed the wet lab study of collecting and dilutions of the sample after stress conditions for the drug sample. MRL also helped in the mobile phase preparation during the HPLC study. All authors read and approved the final manuscript.

\section{Competing interests}

The authors declare that they have no competing interests.

\section{Author details}

${ }^{1}$ Department of Pharmaceutical Analysis, Chebrolu Hanumaiah Institute of Pharmaceutical Sciences, Guntur, Andhra Pradesh 522019, India. ${ }^{2}$ Council for Scientific and Industrial Research (CSIR)-Indian Institute Integrative Medicine, National Institute of Oceanography Regional Centre, Mumbai, India.

Received: 9 July 2016 Accepted: 27 July 2016

Published online: 09 August 2016

\section{References}

Asian Guideline for Validation of Analytical Procedure Adopted from ICH guideline, Q2A27, and ICH Q2B. 1994. 
Bronson J, Black A, Murali Dhar TG, Ellsworth BA, Robert Merritt J. Teneligliptin (antidiabetic), chapter: to market, to market—2012. Annu Rep Med Chem. 2013;48:523-4.

Goda M, Kadowaki T. Teneligliptin for the treatment of type 2 diabetes. Drug today (Barc). 2013:49:615-29.

Halabi A, Maatouk H, Siegler KE, Faisst N, Lufft V, Klause N. Pharmacokinetics of teneligliptin in subjects with renal impairment. Clin Pharmacol Drug Dev. 2013:2:246-54.

Ideta T, Shirakami Y, Miyazaki T, Kochi T, Sakai H, Moriwaki H, Shimizu M. The dipeptidyl peptidase-4 inhibitor teneligliptin attenuates hepatic lipogenesis via AMPK activation in non-alcoholic fatty liver disease model mice. Int J Mol Sci. 2015;16:29207-18.

Kishimoto M. Teneligliptin: a DPP-4 inhibitor for the treatment of type-2 diabetes. Diabetes Metab Syndr Obes. 2013;6:187-95.

Luhar SV, Pandya KR, Jani GK, Sachin B, Narkhed S. Simultaneous estimation of teneligliptin hydrobromide hydrate and its degradation product by RPHPLC method. J Pharm Sci Bioscientific Res. 2016;6:254-61.

Reddy BR, Rao NV. Saraswathi K. IJPROnline: Stability indicating RP-HPLC method for development and validation of teneligliptin hydrobromide hydrate in pure and tablet dosage forms; 2014

Shanthikumar S, Sateeshkumar N, Srinivas R. Pharmacokinetic and protein binding profile of peptidomimetic DPP-4 inhibitor-teneligliptin in rats using liquid chromatography-tandem mass spectrometry. J Chromatogra B. 2015:1002:194-200

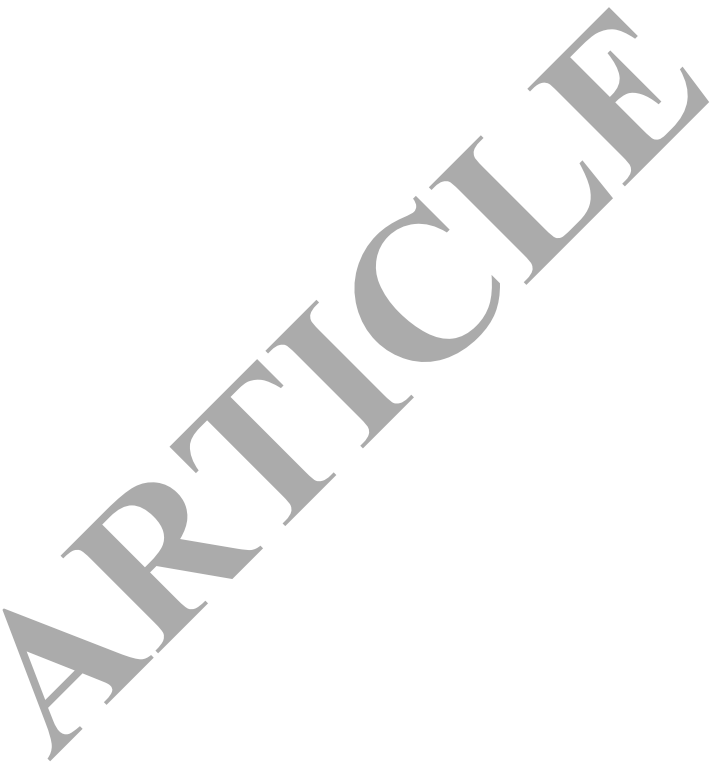

Submit your manuscript to a SpringerOpen ${ }^{\mathcal{O}}$ journal and benefit from:

- Convenient online submission

- Rigorous peer review

- Immediate publication on acceptance

- Open access: articles freely available online

- High visibility within the field

- Retaining the copyright to your article

Submit your next manuscript at $\boldsymbol{\nabla}$ springeropen.com 